\title{
Production of Recombinant Heat Shock Protein 60 (HSP60) From Salmonella enterica serovar Typhimurium ATCC 19585 and Its Evaluation as a Vaccine Candidate in BALB/c Mice
}

\section{Israa F Saied'1, Ghazi M Aziz'1, Ali H Ad'hiah'1 and A Mahdi Saeed²*}

${ }^{1}$ Department of Biotechnology, College of Science, University of Baghdad, Jadriyah, Baghdad, Iraq ${ }^{2}$ Departments of Large Animal Clinical Sciences and Epidemiology, Michigan State University, USA

\begin{abstract}
The gene for heat shock protein 60 (HSP60) was amplified from the DNA extract of Salmonella enterica serovar Typhimurium strain (LT2), ATCC 19585, using Polymerase Chain Reaction (PCR). The HSP60 gene was partially sequenced, inserted into expression vector and cloned into a competent Escherichia coli. The expressed recombinant HSP60 protein was purified by Ni-NTA affinity chromatography. Immunization of BALB/c mice with the purified recombinant HSP60 protein resulted in a significant anti-HSP60 antibody titers. The groups of the immunized and control mice were challenged with lethal doses of S. Typhimurium (LT2) ATCC 19585. Immunized mice had a higher survival rate than control mice suggesting the protective value of the recombinant HSP60 protein used for vaccination.
\end{abstract}

Keywords: Salmonella Typhimurium; Heat shock protein 60 (HSP60); Immunogenicity; Challenge testing

\section{Introduction}

Salmonella serovars are responsible for diseases ranging from mild gastroenteritis to life-threatening systemic infections [1]. Typhoid fever is an acute systemic infection caused by the bacterium Salmonella enterica serovar Typhi. Salmonella enterica serovars Paratyphi A, B and $\mathrm{C}$ cause the clinically similar condition, paratyphoid fever with symptoms, which are milder with lower mortality rate. Typhoid and paratyphoid fevers are collectively referred to as enteric fevers [2]. Non-typhoidal salmonellosis or enterocolitis is caused by at least 150 Salmonella serotype with Salmonella Typhimurium and Salmonella Enteritidis being the most common serotypes causing gastroenteritis of worldwide distribution [3].Numbers of Typhoid cases are relatively low in developed countries. However, non-typhoidal salmonellosis has increased during the last three decades. Non-typhoidal Salmonella infections account for 1.3 billion cases with 3 million deaths $[4,5]$. The emergence of multidrug-resistant strains of Salmonella with increased virulence was associated with increased morbidity and mortality and has further complicated the management of the cases among the infected humans and animals. Currently, there are no efficient vaccines against Salmonella infections and henceforth the continuing efforts for the development of suitable vaccines [6]. Heat shock proteins (HSPs) are highly conserved and abundant proteins in most bacterial species. Although there are several families of molecular sizes of HSP, we decided to choose HSP60 due to its immunogenicity as HSP with smaller molecular sizes tend to be less immunogenic. HSP are often produced in response to a variety of physiological insults and serves to enhance the survival of the bacterial cells under stressful conditions. As a novel vaccination approach, Heat Shock Proteins (HSPs) based-vaccines have become an attractive strategy for disease prevention [7] and they can be early targets in the immune response against a variety of pathogens, they are being exploited as antigens for vaccine development [8]. There is a significant difference between the typhoid fever that is caused by Salmonella Typhi and the non-typhoidal salmonella gastroenteritis that is caused by Salmonella Typhimurium and other non-typhoidal Salmonella serotypes. There is no current effective vaccine for the nontyphoidal Salmonella infections. Therefore the scientific effort for the development of a vaccine against non-typhoidal salmonellosis should be active and continuous to alleviate the millions of cases that impact the human populations worldwide. However, the production of heat shock protein from Salmonella Typhimurium implies the growth and handling of large volumes of the Salmonella culture with the risk of massive contamination of the facility and accidental infection of the operators. Therefore, the objectives of the current study were the production of a recombinant Heat Shock Protein 60 (HSP60) from Salmonella Typhimurium through the cloning of the gene for heat shock protein into a carrier $E$. coli that is safe to handle during culture. The final objective was to evaluate the recombinant heat shock protein as a vaccine candidate in $\mathrm{BALB} / \mathrm{c}$ mice.

\section{Materials and Methods}

\section{Bacterial strains}

Salmonella enterica subspecies enterica serovar Typhimurium (LT2) ATCC 19585 was obtained from American Type Culture Collection (USA). The isolate was used for the extraction of genomic DNA. Escherichia coli One Shot TOP10 chemically competent cells were obtained from Invitrogen Company (USA). All reagents used were of analytical grade.

\section{Bacterial cultivation and DNA techniques}

All bacterial strains were grown in Luria Bertani (LB) medium at $37^{\circ} \mathrm{C}$. Genomic and plasmid DNA was isolated by using the Gentra Puregen cell kit (Qiagen/USA) and QIAGEN plasmid Maxi Kit respectively, as per the manufacturer's instructions. The concentration

*Corresponding author: A Mahdi Saeed, Departments of Large Animal Clinical Sciences and Epidemiology, Michigan State University, East Lansing, Michigan 48824, USA, Tel.: +15174329517; Fax: +15174322310; E-mail: saeeda@msu.edu

Received July 03, 2014; Accepted August 22, 2014; Published August 29, 2014

Citation: Saied IF, Aziz GM, Ad'hiah AH, Mahdi Saeed A (2014) Production of Recombinant Heat Shock Protein 60 (HSP60) From Salmonella enterica serovar Typhimurium ATCC 19585 and Its Evaluation as a Vaccine Candidate in BALB/C Mice. J Microb Biochem Technol 6: 346-350. doi:10.4172/1948-5948.1000166

Copyright: $\odot 2014$ Saied IF, et al. This is an open-access article distributed under the terms of the Creative Commons Attribution License, which permits unrestricted use, distribution, and reproduction in any medium, provided the original author and source are credited 
Citation: Saied IF, Aziz GM, Ad'hiah AH, Mahdi Saeed A (2014) Production of Recombinant Heat Shock Protein 60 (HSP60) From Salmonella enterica serovar Typhimurium ATCC 19585 and Its Evaluation as a Vaccine Candidate in BALB/c Mice. J Microb Biochem Technol 6: 346350. doi:10.4172/1948-5948.1000166

of the eluted genomic DNA was determined spectrophotometrically using Nanodrop ND-1000 (RocLand/USA). Purification of plasmid and PCR product were carried out by QIAquick Gel extraction kit (Qiagen/USA).

\section{Molecular cloning and sequencing}

The full-length of coding region of groEL genes of S. Typhimurium (LT2) ATCC 19585 was amplified by Polymerase Chain Reaction (PCR) using the following sets of primers-Forward primer 5'-ACCATG-GCA-GCT-AAA-GAC-GTA-AAA-TTC-3', which was designed to include a unique NcoI site and the-Reverse primer was 5'-CATCAT-GCC-GCC-CAT-ACC-AC-3', which was designed to remove the native stop codon in the gene of interest and preserve the reading frame through the C-terminal tag (6-His tag). PCR was performed in a PTC100 programmable Thermal Controller (MJ Research.Inc) using initial activation step at $95^{\circ} \mathrm{C}$ for $5 \mathrm{~min}$ followed by 35 cycles of denaturation at $94^{\circ} \mathrm{C}$ for $1 \mathrm{~min}$, annealing at $55^{\circ} \mathrm{C}$ for $1 \mathrm{~min}$ and extension at $72^{\circ} \mathrm{C}$ for $1 \mathrm{~min}$, followed by final extension step at $72^{\circ} \mathrm{C}$ for $10 \mathrm{~min}$. PCR amplified product was resolved in $1 \%$ agarose gel by electrophoresis and visualized by UV-transillumenator. To verify the sizes of the generated fragments, $1 \mathrm{~kb}$ DNA ladder was used. The amplified fragments were cloned into $\mathrm{pBAD}$-TOPO TA expression vector (Invitrogen/USA) in frame with 6-Histidin tag sequence at C-terminal end by the TA cloning techniques, and the derivative was transformed into E. coli One Shot TOP10 (Invitrogen/USA) chemically competent cells. The presence of right gene insert and orientation was confirmed by double digestion of the plasmid with NcoI and PmeI enzymes, plasmid PCR, followed by DNA sequencing at Research Technology Support Facility (RTSF) at Michigan State University.

\section{Expression and purification of recombinant HSP60}

Expression kit (pBAD TOPO TA expression kit/Invitrogen/USA) was used for the expression and purification of recombinant HSP60. Recombinant Heat Shock Protein 60 (HSP60) was purified by (NiNTA) affinity chromatography, which was obtained from Qiagen Company as "QIA expressionist" kit. The purity of the expressed proteins was verified by analysis of the product on $10 \%$ SDS-PAGE along with protein molecular mass marker. Proteins were visualized by staining with Coomassie blue G-250. The eluted protein was dialyzed against distilled water overnight at $4^{\circ} \mathrm{C}$ to remove the urea before lyophalization. The protein concentration was measured by Bradford method [9].

\section{Experimental animals}

After approval from the institutional animal care and use committee at Michigan State University (IACUC), twenty BALB/c mice were purchased from Charles River Laboratories (Boston, MA, USA). Mice were between 6-8 weeks of age and were all females for better handling. Mice were kept in cages and provided with balanced pelleted mouse diet food (Ralston Purina) which meet or exceed the NRC (National Research Council) requirements. Food and water were provided ad libitum. Before the challenge experiment, the immunized and control mice were moved to the University infectious disease containment facility. Michigan State University laboratory animal housing and management are approved by National Institute of Health (NIH) and the United State Department of Agriculture (USDA) and are subject to periodical inspection by these federal agencies.

Immunization of mice: Ten mice were randomly selected for immunization with HSP60 whereas 10 other mice were left as control. A volume of the HSP60 emulsified in Complete Freud's Adjuvant (CFA) was adjusted to contain $30 \mu \mathrm{g}$ of the HSP60 in $100 \mu$ of the emulsion before it was injected subcutaneously into each mouse. For the $2^{\text {nd }}$ and $3^{\text {rd }}$ doses, Incomplete Freund's Adjuvant (ICFA) was used for the emulsification of the same concentrations of HSP60. Immunization was performed at 3 weeks interval between the primary immunizing dose and the first and second booster doses. Control mice were injected with the same material but without the HSP60 using the same schedule.

\section{Determination of antibody titer by ELISA}

The mice were bled prior to the immunization for a baseline measurement of the HSP60 antibody and 7 days after the primary immunization and each booster from the saphenous vein. Blood was allowed to coagulate for several hours at $37^{\circ} \mathrm{C}$ before placing the tubes at $4^{\circ} \mathrm{C}$ at a walking cold room to allow effective shrinkage of the clot before centrifugation at $3000 \mathrm{rpm}$ for $3 \mathrm{~min}$ to collect the serum. Sera were kept at $-20^{\circ} \mathrm{C}$ till used for ELISA measurement of the heat shock protein 60 (HSP60)-specific antibody.

ELISA protocol: ELISA plate wells were coated with $2 \mu \mathrm{g}$ HSP60 was dissolved in carbonate-bicarbonate buffer $(0.05 \mathrm{M}), \mathrm{pH} 9.6$. After usual ELISA steps, plates were read at a $405 \mathrm{~nm}$ in a Molecural devices ThermoMax $^{\circledR}$ plate reader. ELISA titers for sera obtained from the 10 mice prior to immunization had an average OD of 0.013 when measured spectrophotometrically at $405 \mathrm{nM}$.

Such baseline titer may be attributed to exposure of the mice to Salmonella or other gram negative bacteria with shared antigenic constitution to Salmonella.

\section{Challenge experiment}

Salmonella Typhimurium ATCC 19585, the same strain that used to produce the recombinant HSP60 was used as the Live-challenge Salmonella strain. The strain was grown overnight in tryptic soy broth at $37^{\circ} \mathrm{C}$ in an incubator shaker set at $200 \mathrm{rpm}$. It was counted that the overnight culture had $108 \mathrm{CFU} / \mathrm{ml}$ of the broth. Dilutions were made to produce levels of the LD50 (median Lethal Dose) before Intraperitonial Injection (IP) of the vaccinated and control mice. After 7 days of the last vaccination dose, five vaccinated mice and five unvaccinated controls were challenged IP with 100,000 CFU of the live parent strain of the ATCC 19585 Salmonella Typhimurium which is approximately equals to $100 \mathrm{LD} 50$ for this serotype. Another 5 vaccinated mice and 5 unvaccinated mice were challenged with $1000,000 \mathrm{CFU}$ of the strain, which is approximately 1000 LD50 [10,11]. Only 5 mice per LD50 dose were used due to the difficulty in securing approval to use larger number of mice for this experiment. For this number of animals, Fishers exact test was used to reveal the significance of differences in the survival of the immunized and control mice after the challenge. Challenged mice were placed in specially designed cages that minimize environmental contamination at the Infectious Disease Containment facility, Michigan State University. The caged mice were observed 3 times/day for the duration of the experiment. Dead mice were removed from the cages as soon as they were detected.

\section{Results}

The full-length of the Heat Shock Protein 60 (HSP60) of $S$. Typhimurium was amplified from genomic DNA of $S$. Typhimurium ATCC (LT2) 19585. Specific primers were used to amplify the entire gene, which yielded PCR product of approximately 1650 bp (Figure 1). The optimum time of the recombinant protein expression after induction with $0.02 \% \mathrm{~L}$-arabinose was determined, and the result was revealed on SDS-PAGE of the crude and purified GroEL protein, 
Citation: Saied IF, Aziz GM, Ad'hiah AH, Mahdi Saeed A (2014) Production of Recombinant Heat Shock Protein 60 (HSP60) From Salmonella enterica serovar Typhimurium ATCC 19585 and Its Evaluation as a Vaccine Candidate in BALB/c Mice. J Microb Biochem Technol 6: 346350. doi:10.4172/1948-5948.1000166

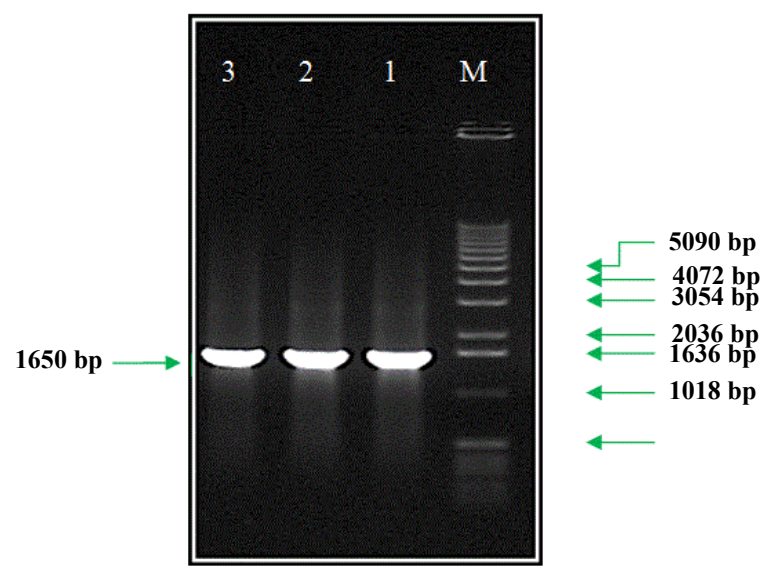

Figure 1: Agarose gel electrophoresis of the amplified shock protein 60 (HSP60) genes using the primer set, on $1 \%$ agarose gel, at $100 \mathrm{~V}$. for 1 hour M: DNA marker. Lane 1, 2 and 3: amplified shock protein 60 (HSP60) gene from S. Typhimurium ATCC 19585 the fragments have size of around $1650 \mathrm{bp}$

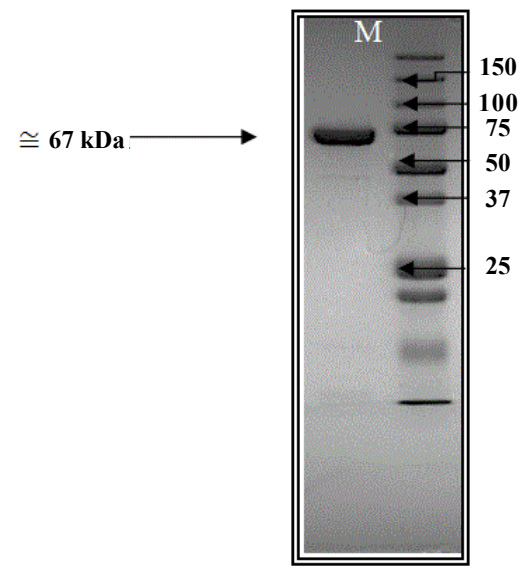

Figure 2: SDS-PAGE analysis of recombinant Heat Shock Protein (HSP60) purified by purification by using Ni-NTA super flow column (affinity chromatography), at 200 V. for 40 minutes, M: Protein marker, 1: Purified Heat Shock Protein (HSP60).

which indicated that the optimum time of protein expression was after 5 and 6 hours of induction with $0.02 \%$ L-arabinose, while the Bradford method that was used to determine the concentration of the purified GroEL protein (By using Ni-NTA spin columns) indicated that the protein concentration was increased with increasing the time of induction, with no significant difference between the protein concentration at the 4,5 and 6 hour times of induction. The protein concentrations were $102,85,100 \mu \mathrm{g} / \mathrm{ml}$. Therefore, the 4 hours' time was considered as the optimum time of induction in this study to avoid long time of incubation of the recombinant protein because it leads to increase the protein degradation. ATCC (3-1) clone was chosen to be used in the next experiments, because it showed high protein expression after determination of the GroEL concentration from the purification step of protein at the optimum time. The purified PCR products of was submitted to the Research Technology Support Facility (RTSF) at Michigan State University for sequencing and the sequence was compared with groEL sequence of $S$. Typhimurium LT2 from the GenBank library. The sequenced part of the gene by RTSF was found to be identical to the sequence of GenBank. The gene that was inserted into $\mathrm{pBAD}$ TOPO expression vector was then cloned into $E$. coli and the expression of the recombinant protein was induced by $0.02 \%$ of L-arabinose in the growth medium. The protein was predominantly expressed in insoluble form and was purified by (Ni-NTA) affinity chromatography under denaturing conditions of SDS-PAGE (10\%) electrophoresis. Analysis of the purified protein revealed a single band of approximately $65-67 \mathrm{kDa}$ (Figure 2 ). The eluted protein was dialyzed against distilled water overnight at $4^{\circ} \mathrm{C}$ to remove the urea, and then the protein was filter-sterilized before using for immunization of $\mathrm{BALB} / \mathrm{c}$ mice.

ELISA Measurement of amplified Heat Shock Protein 60 (HSP60)specific Antibody in Sera of Vaccinated Mice

Result of ELISA testing of sera from the vaccinated mice during the 9 weeks of vaccination is depicted in (Figure 3). The 3 points represent the means of triplicate values from the 10 vaccinated mice, which were 0.226 for the first immunization dose $(30 \mu \mathrm{g}$ GroEL+CFA) and 0.276 and 0.616 for the two booster doses with $(30 \mu \mathrm{g}$ HSP60+ICFA) respectively, with 3 weeks intervals between each dose. The trend suggests a progressive rise in the titer of the anti-HSP60 antibody to a significant level by the end of the 9 weeks. This suggests that the adjuvanted HSP60 injected subcutaneously into the BALB/c mice has a good immunogenic property. Sera obtained from the control mice did not reveal any significant level of the anti-HSP60 antibody.

\section{Challenge experiment}

To demonstrate the effectiveness of the protective effect of the heat shock protein 60 , the survival of the vaccinated and control mice, after challenge, was measured (Figure 4). It is noteworthy that all the control mice that received the 1000 LD50 of the challenge Salmonella died after 72 hours whereas the vaccinated mice survived the same challenge dose of the organism for that period of observation. Due to the small number of animals Fishers exact test was used (Fisher exact test, $\mathrm{P}$-value $=0.0039)$ [12].

However one mouse of the vaccinated group that was challenged by the 100 LD50 died after 72 hours. The overall survival of the vaccinated

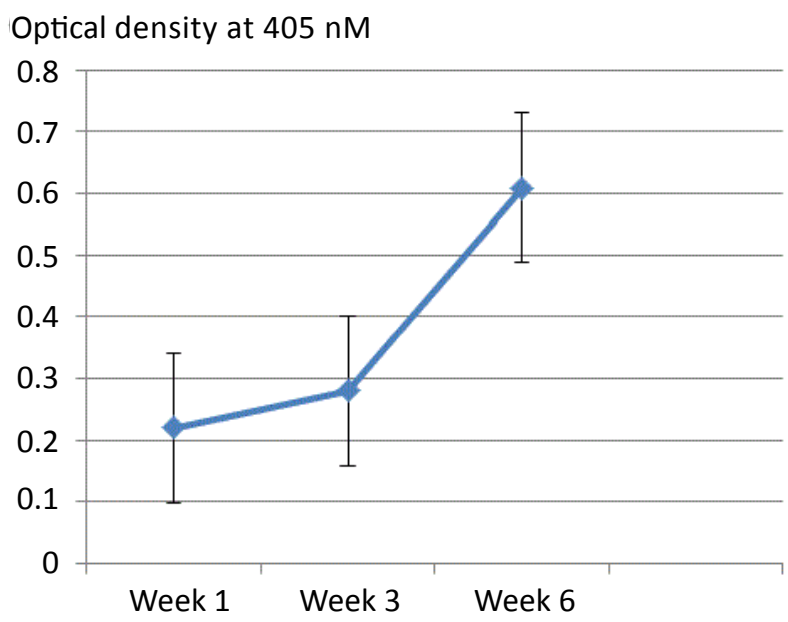

Figure 3: Time course study of the immune response of BALB/c mice immunized with $30 \mu \mathrm{g}$ heat shock protein 60 at 3 weeks intervals. Each point represents the mean and standard errors of serum IgG from 10 mice measured by ELISA. Mean OD titers for the mice before immunization was "0.013). 


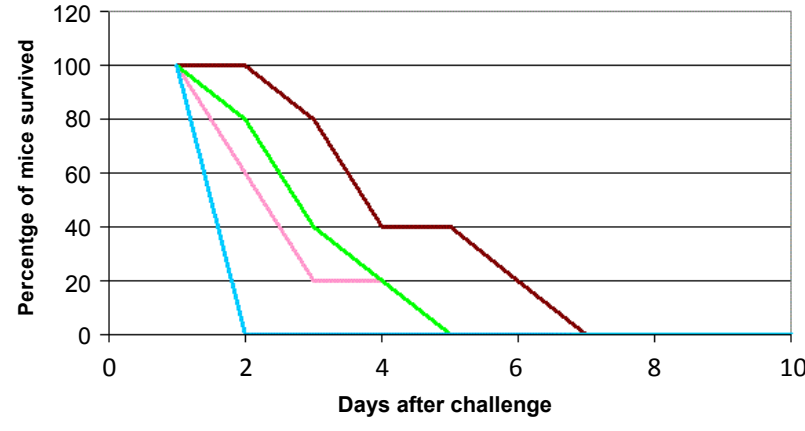

Figure 4: Survival curve of BALB/c mice against lethal dose of $S$. Typhimurium ATCC 19585. Red line: vaccinated mice challenged with 100 LD50 dose, Green line: Vaccinated mice challenged with 1000 LD50 dose, Pink line: Control mice challenged with 100 LD50 dose, Sky blue line: control mice challenged with 1000 LD50 dose.

mice compared to control mice throughout the challenge experiment suggests the protective value of the HSP60 among the vaccinated mice in comparison to the control mice. Most of the reported challenge experiments used a significantly lower challenge LD50. However, due the limited number of mice approved by IACUC, we had to design the challenge experiment using a higher LD50 to capture the differences in resistance between the vaccinated and the control mice to the challenge.

\section{Discussion}

Purification is vital for the characterization of the function, structure, and interactions of any protein targeted for study. Regarding Heat Shock Proteins (HSP), different traditional methods of purification of the native forms of these proteins have been reported [13]. Adopted the Fast Protein Liquid Chromatography (FPLC) using Mono Q HR (5/5) ion-exchange column to purify the $66-\mathrm{kDa}$ HSPs of Salmonella Typhimurium, and the purified protein was found to be free of any other protein contaminants after analyzing by SDSPAGE. As for the purification of recombinant HSP60 protein from different bacterial isolates, series of purification procedures including column chromatography on DEAE-cellulose, hydroxyapatite and Sephacryl S-200 were used [14]. With the advent of genetic engineering, it has become relatively easy to clone the cDNA encoding a given protein. It is then possible to construct an overproducing strain of $E$. coli that can be induced to produce large amounts of a desired gene product. Affinity chromatography is one of the most important and powerful method since it can offer high selectivity, high resolution, and high capacity for target proteins [15]. Significant number of studies has been conducted on S. Typhimurium because it is the leading cause of human gastroenteritis a foodborne disease in humans and a significant pathogen in domestic animals. This serovar also causes a typhoid-like disease in mice which is found a very good model in order to understand typhoid fever, a disease affecting millions of people worldwide annually and caused by $S$. Typhi $[6,16]$. Heat shock proteins are highly conserved as the encoding gene for which is also known as groEL, is known to be among the most conserved components in evolution. The groEL gene has become as a target gene in typing and identification of Salmonella, Campylobacter jejuni, Staphylococcus and Bacillus cereus [17-20].

In this study, we report the design and production of a recombinant Heat Shock Protein 60 (HSP60) from S. Typhimurium and the evaluation of its immunogenic property in mice. The fact that HSPs are targets of the immune response in a broad spectrum of infections may be related to the abundance of these proteins under stress conditions.
For example, GroEL is one of the most abundant proteins expressed by salmonellae within infected macrophages, which are known to be critical antigen-presenting cells in the immune system. Given the potential importance of HSPs, it was of interest to identify and characterize immunogenic epitopes within this protein, as has been done with some pathogens and they indicated shared epitopes between them; e.g. Escherichia coli HSP60 (GroEL), GroEL of S. Typhi, HSP60 of Chlamydia trachomatis and HSP65 Mycobacterium tuberculosis [21,22]. Microbial HSPs have been reported to be dominant antigens for the host immune response to a variety of pathogens and the immune recognition of these HSPs serves as a first line of defense and a number of studies reported significant protection by using HSPs as vaccines in various infectious disease models [23].

The relative resistance of the HSP-immunized mice can be explained by the fact that during microbial infections, HSP determinants are expressed on the cell surface and can be recognized by antibodies induced by the immunization of mice with HSP60. Tobian et al. [24] reported that recombinant HSP fusion proteins (with antigenic sequences fused to the $\mathrm{N}$ or $\mathrm{C}$ terminus of the HSP60were associated with eliciting $\mathrm{CD} 8+\mathrm{T}$ cell and $\mathrm{Ab}$ responses. The observed antibody-mediated protection in the present study could be attributed to surface localization of the HSP60 (GroEL). Our challenge results agree with other results of GroEL immunization and challenge studies on BALB/c mice. Khan et al. [25] demonstrated that the onset of death of immunized mice with GroEL was insignificantly delayed and all the mice died by the seventh day post-infection after they were challenged with $105 \mathrm{CFU}$ of S. pneumoniae. As well as, Pinho and his co-worker showed that the rate of survival of the animals immunized with recombinant HSP60 was slightly higher than that of mice injected with PBS; however, all the animals died within two weeks after challenged with $106 \mathrm{CFU}$ of the virulent $C$. pseudotuberculosis [26]. Therefore, our results can give strong evidence that immunization of animals with GroEL elicited a good humoral response. Antibodies response has been reported to play an important role in protection against Salmonella infection in mice $[27,28]$.

\section{Conclusion}

It was possible to clone and express the gene for Heat shock protein 60 (GroEL) of S. Typhimurium (LT2) ATCC 19585104 into a competent E. coli. Purified recombinant HSP60 (GroEL) has good immunogenic properties based on the immunization of $\mathrm{BALB} / \mathrm{c}$ mice. Furthermore, Immunization of mice with the recombinant GroEL induced measurable protection against a challenge lethal dose of the parent S. Typhimurium (LT2) ATCC 19585 serotype and therefore suggests the potential value of recombinant HSP60 as a possible vaccine candidate for preventing salmonellosis in humans and animals.

\section{Acknowledgment}

The authors would like to express their thanks and appreciation to Mr. Randy Shoemaker, supervisor of the laboratory Animal Facilities and his staff at Michigan State University for their valuable support.

\section{Conflict of Interest}

All authors declare that they have no financial and/or personal relationship with any organization that may inappropriately influence their work.

\section{References}

1. Fardini Y, Chettab K, Grepient O, Rochereau S, Trotereau J, et al. (2007) The Yfgel lipoprotein is essential for type III secretion-system expression and virulence of Salmonella Enteritidis. Infection and Immunity 75: 358-370.

2. Parry CM (2006) Epidemiology and Clinical Aspects of human typhoid fever. In 
Citation: Saied IF, Aziz GM, Ad'hiah AH, Mahdi Saeed A (2014) Production of Recombinant Heat Shock Protein 60 (HSP60) From Salmonella enterica serovar Typhimurium ATCC 19585 and Its Evaluation as a Vaccine Candidate in BALB/c Mice. J Microb Biochem Technol 6: 346350. doi:10.4172/1948-5948.1000166

Matroeni P and Maskell D (Eds.) Salmonella infections: Clinical, immunological and molecular aspects, P.1-8, New York: Cambridge University Press.

3. Gray TT, Fedorka-Cray PJ (2002) Salmonella. In Cliver DO and Riemann HP (Eds.) Foodborne diseases, p.55-68, San Diego: Academic Press.

4. Hu L, Kopecko DJ (2003). Typhoid Salmonella. In Millotics MD and Bier JW (Eds.). International handbook of foodborne pathogens, P.151-165. New York: Marcel Dekker, Inc.

5. Pui CF, Wong WC, Chai LC, Tunung R, Jeyaletchumi P, et al. (2011) Review Article: Salmonella: A food borne pathogen. International Food Research Journal 18: 465.

6. Hamid N, Jain SK (2008) Characterization of an outer membrane protein of Salmonella enterica serovar Typhimurium that confers protection agains Typhoid. Clinical and Vaccine Immunology 15: 1461-1471.

7. Serensen JG, Kristensen TN, Loeschcke V (2003) The evolutionary and ecological role of heat shock proteins. Ecology Letters 6: 1025-1037.

8. Desai NS, Agarwal AA, Uplap SS (2010) HSP: evolved and conserved proteins structure and sequence studies. International Journal of Bioinformatics Research 2: 67-87.

9. Bradford MM (1976) A rapid and sensitive method for the quantitation of microgram quantities of protein utilizing the principle of protein-dye binding. Anal Biochem 72: 248-254.

10. Isibasi A, Ortiz V, Vargas M, Paniagua J, Conzales C, et al. (1988) Protection against Salmonella Typhi infection in mice after immunization with outer membrane proteins isolated from Salmonella Typhi 9, 12, d, Vi. Infect Immun 56: 2953-2959

11. Nnalue NA (1990) Mice vaccinated with a non-virulent, aromatic dependent mutant of Salmonella choleraesuis die from challenge with it virulent paten but survive challenge with Salmonella Typhimurium. Journal of Medical Microbiology 31: 225-233.

12. Fisher $R$ (1955) Statistical methods and scientific induction. Journal of royal statistical society. Series B (Methodological) 17: 69-78.

13. Ensgraber M, Loos M (1992) A 66-kilodalton heat shock protein of Salmonella typhimurium is responsible for binding of the bacterium to intestinal mucus. Infect Immun 60: 3072-3078.

14. Spence J, Georgopoulos C (1989) Purification and properties of the Escherichia coli heat shock protein, HtpG. J Biol Chem 264: 4398-4403.

15. Simpson RJ (ed.) (2004) Purifying proteins for proteomics: A laboratory manual Cold Spring Harbor Press, Cold Spring.

16. McClelland M, Sanderson KE, Spieth J, Clifton SW, Latreille P, et al. (2001)
Complete genome sequence of Salmonella enterica serovar Typhimurium LT2. Nature 413: 852-856

17. Goh SH, Potter S, Wood JO, Hemmingsen SM, Reynolds RP, et al. (1996) HSP60 gene sequences as universal targets for microbial species identification: studies with coagulase-negative staphylococci. J Clin Microbiol 34: 818-823.

18. Nair S, Lin TK, Pang T, Altwegg M (2002) Characterization of Salmonella serovars by PCR-single-strand conformation polymorphism analysis. J Clin Microbiol 40: 2346-2351.

19. Chang YH, Shangkuan YH, Lin HC, Liu HW (2003) PCR assay of the groEL gene for detection and differentiation of Bacillus cereus group cells. Appl Environ Microbiol 69: 4502-4510.

20. Karenlampi RI, Tolvanen TP, Hanninen ML (2004) Phylogenetic analysis and PCR-Restriction fragment Length Polymorphism Identification of Campylobacter species based on partial groEL gene sequence. J Clin Microbio 42: $5731-5738$.

21. Perschinka H, Mayr M, Millonig G, Mayerl C, van der Zee R, et al. (2003) Crossreactive B-cell epitopes of microbial and human heat shock protein 60/65 in arthrosclerosis. Arterioscler Thromb Vasc Biol 23: 1060-1065.

22. Bansal A, Paliwal PK, Sagi SS, Sairam M (2010) Effect of adjuvant on immune response and protective immunity elicited by recombinant HSP60 (GroEL) of Salmonella Typhi against S. Typhi infection. Mol Cell Biochem 337: 213-221.

23. Tsan MF, Gao B (2009) Heat shock proteins and immune system. J Leukoc Biol 85: 905-910.

24. Tobian AA, Harding CV, Canaday DH (2005) Mycobacterium tuberculosis hea shock fusion protein enhances class I MHC cross processing and presentation by B-Lymphocytes. J Immunol 174: 5209-5214.

25. Khan MN, Shukla D, Bansal A, Mustoori S, Ilavazhagan G (2009) Immunogenicity and protective efficacy of GroEL (hsp60) of Streptococcus pneumoniae against lethal infection in mice. FEMS Immunol Med Microbiol 56: 56-62.

26. Pinho JMR, Dorella FA, Coelho KS, Fonseca CT, Cardoso FC, et al. (2009) Immunization with recombinant Corynebacterium pseudotuberculosis heat shock protein (Hsp)-60 is able to induce an immune response in mice, but fails to confer protection against infection. The Open Veterinary Science Journal 3 : 22-27.

27. Secundino I, López-Macías C, Cervantes-Barragán L, Gil-Cruz C, Ríos Sarabia N, et al. (2005) Salmonella porins induce a sustained, lifelong specific bactericidal antibody memory response. Immunology 117: 59-70

28. Sood S, Rishi P, Vohra H, Sharma S, Ganguly NK (2005) Cellular immune response induced by Salmonella enterica serotype Typhi iron-regulated outermembrane proteins at peripheral and mucosal levels. J Med Microbiol 54: 815821. 